\section{Cancer Proliferation}

\section{E. Boyland}

Cancer Chemotherapy and Pharmacology. Editors S.K. Carter et al. 3/yr. (Springer-Verlag.) DM178. Cancer Genetics and Cytogenetics. Editor-in-chief A.A. Sandberg. $8 / \mathrm{yr}$ in 2 vols. (Elsevier/ North-Holland Biomedical.) \$202. Carcinogenesis. Executive editors A. Dipple and R.C. Garner. 12/yr. (IRL Press, London.) £90. Environmental Mutagenesis. Editor-in-chief S. Abrahamson. 6/yr. (Alan R. Liss.) $\$ 90$ US, $\$ 106.50$ Europe. Oncodevelopmental Biology and Medicine. Editors-in-chief W.H. Fishman and H. Hirai. 6/yr. (Elsevier/NorthHolland Biomedical.) Dfl. 202.

THOSE working in cancer research are in danger of being overwhelmed with published material. There are dozens of specialized cancer journals, as well as reports of congresses and symposia, reviews and monographs. And more general publications, such as Nature, Science and The Lancet, remain compulsory reading for those in the field.

Historically, publications on cancer first appeared in the journals of pathology, notably in Archiv für Pathologische Anatomie (Virchows Archiv), which started in 1847, and the Journal of Pathology and Bacteriology, first published in 1892. The first specifically cancer journal appears to have been Revue des Maladies Cancereuses, which was published from 1895 until 1901. Zeitschrift für Krebsforschung which was started in 1904 recently changed its name to the Journal of Cancer Research and Clinical Oncology. The Joumal of Cancer Research started in 1916, became the American Journal of Cancer in 1931 and Cancer Research in 1941. Since then, so many journals dealing with cancer and genetics have appeared that it is difficult for investigators to be aware of progress. Keeping abreast is easier if the titles of the papers in journals are listed either in Current Contents or in Index Medicus.

During the past two years, at least five new journals have appeared. Cancer Chemotherapy and Pharmacology carries reviews and original papers dealing with both experimental and clinical chemotherapy of cancer. Contributions appear in this journal from laboratories all over the world and, importantly, it is indexed in Current Contents. Many of the agents used in cancer therapy are carcinogenic, so that the journal is also of interest to scientists working on the causes of cancer.

Cancer Genetics and Cytogenetics covers "various areas of genetics and cytogenetics (e.g. human, animal, molecular, population, biochemical) as they relate to the broad fields of cancer, in order to reach as multidisciplinary an audience as possible"'. The journal attempts to cover the gap between research into phenomena in animals and human beings, and thus has an essential role to play.

Carcinogenesis is a well-produced, largeformat journal. It accepts full papers and short communications "in the areas of carcinogenesis; mutagenesis; factors modifying these processes such as DNA repair; genetics and nutrition; metabolism of carcinogens; the mechanism of action of carcinogens and promoting agents; epidemiological studies; and the formation, detection, identification and quantification of environmental carcinogens". Most of the contributions are from leaders in the field, many of whom are biochemists.

\section{Cancer Generics and $C$ yrogeneric}

The two remaining journals both have the support of professional bodies. Environmental Mutagenesis (EM), the official organ of the Environmental Mutagen Society, is geographically limited compared with the other periodicals whereas the rest have international editorial boards, that of EM is drawn solely from North America. Nonetheless the strength of research done in the USA in this area is probably enough to support the journal, which appears to be doing well: frequency of publication has increased from four to six issues per year. The journal publishes original papers, brief communications and reports of meetings.

Oncodevelopmental Biology and Medicine is the journal of the international society of the same name. The journal is concerned with new proteins, such as the carcino-embryonic antigens (CEA) which are associated with cancer. Certainly, there should be no shortage of papers for this journal - immunology is a subject which is particularly actively pursued at the moment, and might even be termed the current band-wagon.

All of these five journals are publishing interesting, new, original work and are well produced. They are all specialized and will probably be read only by workers in the fields which each journal covers. Thus they are unlikely to attract subscriptions from general libraries.

Some publishers of scientific journals charge authors for editors to look at new papers or to publish them, but it appears that none of these asks for payment. (One is reminded of Samuel Johnson's saying " no man but a blockhead ever wrote except for money.") But will libraries and laboratories be able to afford them? Many specialist libraries are now so short of money and of space to house the flood of published material that the answer may be disappointing. In the circumstances, one must admire the enterprise of the editors and publishers involved and wish them well.

E. Boyland is an Emeritus Professor of Biochemistry at the London School of Hygiene and Tropical Medicine.

\section{Pharmacology Issues}

\section{Hilary G. Pickles}

Journal of Cardiovascular Pharmacology. Editors-in-chief J. Koch-Weser and L.I. Goldberg. 6/yr. (Raven.) \$63 US, $\$ 75$ elsewhere (personal); $\$ 88$ US, $\$ 96$ elsewhere (institutional). Journal of Ethnopharmacology. Editors L. Rivier and J.G. Bruhn. 6/yr. in 2 vols. (Elsevier Sequoia.) SwFr. 330. Neurotoxicology. Editor Joan Cranmer. 4/yr. (Pathotox, Park Forest South, Illinois.) \$29 (personal); $\$ 60$ (institutional). Journal of Pharmacological Methods. Editors-inchief P.S.J. Spencer and J.H. McNeill. $8 / \mathrm{yr}$ in 2 vols. (Elsevier/North-Holland Biomedical.) \$188. Methods and Findings in Experimental and Clinical Pharmacology. Editor J.R. Prous. 6/yr. (J.R. Prous, Barcelona.) $\$ 100$. Reviews in Pure \& Applied Pharmacological Sciences. Editor-in-chief M. Segal. 4/yr. (Freund, Tel Aviv/Wiley.) $\$ 85$.

OF THE six new journals covered here, Raven's Journal of Cardiovascular Pharmacology (JCP) appears to provide the best value for both subscribers and contributors. At $\$ 80$ a year (1981 prices) for an institutional subscription in the UK, there are six issues annually, currently containing over 20 papers and 250 pages each, as well as occasional supplements of symposium proceedings. For contributors, JCP offers relatively quick publication (delays of between four and seven months) and appearance in a journal which already has a "name"'. Additionally, there are no page charges.

JCP aims to bring together material from laboratory workers and clinicians, and at present just under a third are research reports on human and clinical studies, with the remainder split between in vivo and in vitro animal work. Despite its slightly ambiguous title, JCP is a journal for pharmacologists; even the clinical material would appeal more to clinical pharmacologists than to cardiologists. The papers themselves are very varied in standard, but the journal can hardly be accused of parochialism in that contributions from throughout the world are published. Doubtless this is due to the influence of an enormous editorial board - over one hundred members from 19 countries.

Interestingly, only a small proportion of the papers in the regular issues come from a commercial address, which in this case at least gives no support to the prejudice that the proliferation in pharmacological journals is encouraged by a publicityconscious pharmaceutical industry.

In contrast to the broad scope of JCP, the Journal of Ethnopharmacology (JE) is laying claim to what I imagine to be a very small niche indeed. It is concerned with

the observation, description and experimental investigation of the biological 